\title{
CIRUGÍA DEL PTERIGION: UNA HISTORIA QUE AÚN NO TERMINA
}

\author{
ROJAS-ALVAREZ E ${ }^{1}$
}

Por su apariencia antiestética y su naturaleza progresiva, el pterigion es una de las más antiguas afecciones oculares descritas. Desde tiempos remotos los más famosos médicos ya lo conocían y hacían descripciones precisas de sus diversas formas. Los estudios iniciales realizados por el médico hindú Susruta, considerado como el primer cirujano oftalmólogo, datan de mil años a.C. Describió con precisión el pterigion, su tratamiento, así como su fácil recidiva.

Hipócrates (469 a.C.) sugirió el tratamiento con zinc, cobre, hierro, bilis, orina y leche materna. Celso (50 d.C.) y Galeno (131 d.C.) trataron el pterigion con soluciones de vino blanco, vinagre, azúcar, así como su pinzamiento y exéresis (1).

En la medicina árabe algunos puntos son llamativos, como el tratamiento para el sangrado postoperatorio del pterigion con una mezcla de sal y alcaravea mascada y luego presionada a través de una pieza de ropa por donde se filtraban las gotas.

En el texto oftalmológico «Memorial de los oculistas de Ali Ibn Isa», se utiliza la palabra «tanwim», que significa literalmente «poner a dormir», cuando se refiere a las de cirugías oftalmológicas en pacientes que no pueden estarse quietos. Todas las traducciones de los textos al latín interpretan dicha palabra como dormir, o dar somníferos, o paciente dormido. Todas las citas en las que se usa la palabra «tanwim»se refieren a operaciones oftalmológicas largas y dolorosas (pterigion, pannus, etc.).

Khalifah, del período tardío de la medicina árabe, nos deja en sus tratados ilustraciones de instrumentos oftálmicos, en un número superior que cualquier otro libro medieval (2). Encontramos en este manuscrito 36 ilustraciones en dos páginas, donde se explican algunos instrumentos de la cirugía de pterigion como:

Miqrad: tijeras estrechas usadas para cortar el pterigion de la conjuntiva.
Kaz: tijeras con una hoja más estrecha que la primera usadas para cortar el pterigion del limbo.

Sananir: ganchos usados para levantar el pterigion y escindirlos.

Asah: (la oja de un myrtle) usado para elevar el pterigion y pelarlo.

El tiempo impuso retos superiores a esta historia. En el año 1872 Arlt describe la autoplastia conjuntival, proceder que ha pasado por distintas etapas de uso y desuso. Es una técnica factible de realizar en nuestro medio (3).

Thoft introdujo la utilización de autoinjertos conjuntivales para la reconstrucción de la superficie ocular. La técnica se basa en el uso de membrana mucosa conjuntival normal con su red vascular superficial intacta y con las células de la superficie sanas de forma que se tiene una fuente normal de células caliciformes, de superficie columnar y de células madre para reponer la membrana lesionada.

Con los nuevos caminos que año tras año fue tomando la cirugía de pterigion, se fueron observando diversas variaciones en el uso de la superficie de autoinjerto conjuntival, entre ellas: transposición conjuntival ortotópica libre, autoinjerto rotatorio conjuntival, transposición del colgajo conjuntival inferior, técnica de colgajo conjuntival mínimo y pedículo conjuntival limbar.

Aunque la técnica pueda ser difícil para un cirujano principiante, sus resultados funcionales y cosméticos la han hecho muy popular para tratar el pterigion primario y secundario. Con esta técnica no se han encontrado otras complicaciones, su única limitación es que no haya disponibilidad de conjuntiva sana en el ojo afectado o en el contralateral, o cuando se prevea la realización de cirugía de glaucoma, en cuyo caso la técnica no es aplicable (3).

El año 1946 trae un nuevo paso en esta historia. Magitot describió por primera vez la queratoplastia lamelar como un tratamiento para el pterigion recidi-

\footnotetext{
1 Doctor en Medicina. Facultad Cubana de Oftalmología. Ciudad de La Habana. Cuba.

E-mail: dr_erojas@yahoo.es
} 
vante. Al cubrir los defectos del tejido se suprime la cicatrización del pterigion recurrente con tejido lamelar corneoescleral del ojo donante y se consigue un efecto barrera del crecimiento vascular y del desarrollo de una nueva fibrosis en la superficie corneal. Las complicaciones que se han observado son hemorragia intralamelar, depósitos de hemosiderina e infección del injerto. La única desventaja que presenta esta técnica es la disponibilidad de tejido del donante y la utilización de esteroides e inmunosupresores durante un prolongado período de tiempo (3).

El uso de la mitomicina $C$ en la cirugía de pterigion comenzó en la década de 1990 pero sólo hasta finales de la misma se estableció su óptima concentración y modo de aplicación para disminuir los pocos efectos adversos deseados (glaucoma secundario, edema corneal, cataratas, perforación corneal o escleral).

Es un agente antineoplásico derivado del Streptomyces caespitosus cuyo principal efecto en el tratamiento del pterigion es inhibir la síntesis de ADN a nivel de fibroblastos y linfocitos. Sus efectos, los cuales son dosis-dependientes, continúan hasta 36 días después de aplicada y se ha demostrado que la dosis ideal en la cirugía de pterigion es de $0,04 \%$ utilizada durante un minuto sobre la esclera desnuda en donde se ha resecado el tejido anormal proliferante, antes de realizar la plastia conjuntival.

Los injertos de mucosa bucal se han utilizado en oftalmología para reconstruir el fórnix, los párpados y el agujero orbital. En el tratamiento del pterigion, proporcionan una fuente alternativa de membrana mucosa cuando no hay suficiente conjuntiva en el ojo y dicha cobertura de membrana mucosa previene que vuelva a crecer el pterigion (4).
Muchas son las técnicas y terapias que se han utilizado para prevenir las recurrencias, como antimetabolitos, radioterapia, autoinjerto de conjuntiva con o sin injerto de células límbicas y en los últimos años se ha popularizado el uso de la membrana amniótica como método para disminuir la recidiva del pterigion.

Múltiples han sido los intentos terapéuticos ensayados sin alcanzar éxito definitivo en el tratamiento del pterigion. Ésta es una afección de tratamiento netamente quirúrgico y en el camino por el logro de la perfección necesaria han surgido innumerables técnicas que se emplean indistintamente de acuerdo con la particularidad de cada paciente o cirujano; pero aún así, ubicados en el siglo XXI, con el enorme desarrollo científico-técnico alcanzado en los últimos años y con los adelantos en cirugía ocular, que hace apenas unas décadas parecían solo ficción, resulta desalentador que el pterigion siga constituyendo un problema objetivo en la práctica oftalmológica, con una frecuencia de recidiva entre el $20 \mathrm{y}$ el $40 \%$ con las técnicas convencionales (4).

\section{BIBLIOGRAFÍA}

1. Vaugham D. Enfermedades de la conjuntiva. En: Vaugham D, Asbury T, Riordan-Eva P. Oftalmología general. México, DF: El manual moderno; 1994; 133.

2. Cristóbal Bescós JA. La oftalmología medieval. El legado de los árabes. Rev Microcirugía Ocular 2005; 4.

3. Guilarte ED. Estudio comparativo entre la escisión de pterigion primario con autoinjerto conjuntival y el cierre primario. Revista 16 de abril, La Habana, 2006.

4. Aragonés B. Estudio prospectivo de trasplante conjuntival con células límbicas o sin ellas, en el pterigion primario. Rev Cub Oftalmol 2006; 19. 